Special issue in honor of Prof. George C. Papageorgiou

\title{
Photosynthetic response of lutein-deficient mutant lut2 of Arabidopsis thaliana to low temperature at high light
}

\author{
A.V. POPOVA*, (iD, R. VLADKOVA* (D), P. BORISOVA*, K. GEORGIEVA** (D), \\ G. MIHAILOVA** (iD), V. VELIKOVA** iD , T. TSONEV ${ }^{* *}$ (iD), and A.G. IVANOV,*** id \\ Institute of Biophysics and Biomedical Engineering, Bulgarian Academy of Sciences, Acad. G. Bonchev Str., \\ Bl. 21, 1113 Sofia, Bulgaria* \\ Institute of Plant Physiology and Genetics, Bulgarian Academy of Sciences, Acad. G. Bonchev Str., Bl. 21, \\ 1113 Sofia, Bulgaria** \\ Department of Biology, University of Western Ontario, 1151 Richmond Str. N., London, N6A 5 B7 Ontario, \\ Canada ${ }^{* * *}$
}

\begin{abstract}
Alterations in photosynthetic performance of lutein-deficient mutant lut2 and wild type (wt) of Arabidopsis thaliana were followed after treatment with low temperature and high light for $6 \mathrm{~d}$. The obtained results indicated lower electrolyte leakage, lower excitation pressure, and higher actual photochemical efficiency of PSII in lut 2 plants exposed to combined stress compared to wt plants. This implies that lut2 is less susceptible to the applied stress conditions. The observed lower values of quantum efficiency of nonphotochemical quenching and energy-dependent component of nonphotochemical quenching in lut2 suggest that nonphotochemical quenching mechanism(s) localized within LHCII could not be involved in the acquisition of higher stress tolerance of lut 2 and alternatives to nonphotochemical quenching mechanisms are involved for dissipation of excess absorbed light. We suggest that the observed enhanced capacity for cyclic electron flow and the higher oxidation state of $\mathrm{P}_{700}\left(\mathrm{P}_{700}{ }^{+}\right)$, which suggests PSI-dependent energy quenching in lut 2 plants may serve as efficient photoprotective mechanisms, thus explaining the lower susceptibility of lut 2 to the combined stress treatments.
\end{abstract}

Keywords: abiotic stress; carotenoid mutant; energy partitioning; photoprotection; photosynthetic performance.

\section{Introduction}

The photosynthetic process, driven by coordinated functioning of the main pigment-protein complexes in the thylakoid membranes, is extremely sensitive to different abiotic stressors that very often act simultaneously. Higher plants respond to adverse stress conditions at multiple levels ranging from leaf morphology and chloroplast

\section{Highlights}

- Part of excessive absorbed light is quenched by constitutive thermal dissipation

- In lut2 plants, the initial capacity for CEF is higher than that in wt

- lut2 mutation seems to affect $\mathrm{P}_{700}{ }^{+}$oxidation probability
Received 28 September 2021

Accepted 16 February 2022

Published online 1 March 2022

${ }^{+}$Corresponding author

phone: +35929793681

e-mail:popova@bio21.bas.bg

Abbreviations: $\mathrm{AL}$ - actinic light; $\mathrm{CEF}$ - cyclic electron flow around PSI; Chl - chlorophyll; $\mathrm{F}_{0}$ - minimal fluorescence yield of the dark-adapted state; $\mathrm{F}_{0}{ }^{\prime}$ - minimal fluorescence yield of the light-adapted state; $\mathrm{F}_{\mathrm{m}}$ - maximal fluorescence yield of the dark-adapted state; $F_{m}{ }^{\prime}-$ maximal fluorescence yield of the light-adapted state; $F_{v}-$ variable chlorophyll fluorescence; $F_{v} / F_{m}-$ maximal quantum yield of PSII photochemistry; LCP - light-compensation point; MT - multiple-turnover flash; NPQ - nonphotochemical quenching; $\mathrm{P}_{700}$ - reaction center chlorophyll of PSI; $\mathrm{P}_{700}{ }^{+}$- oxidized form of PSI reaction center; $P_{\mathrm{Nmax}}$ - saturating level of oxygen evolution; $\mathrm{PQ}$ - plastoquinone; $\mathrm{q}_{\mathrm{E}}$ - energy-dependent component of NPQ; R - recovery; ST - single-turnover flash; WUE - water-use efficiency; $\Phi_{\mathrm{f}, \mathrm{D}}-$ quantum yield of nonregulated energy dissipation of PSII; $\Phi_{\mathrm{NPQ}}$ - quantum yield of the regulated energy dissipation of PSII; $\Phi_{\text {PSII }}$ - actual photochemical efficiency of PSII.

Acknowledgments: This work was financially supported by Bulgarian Science Fund under project КП-06-H26/11. The seeds of the wt and mutant lut 2 of Arabidopsis thaliana were a generous gift from Prof. R. Bassi.

Conflict of interest: The authors declare that they have no conflict of interest. 
ultrastructure (Walters 2005) to physiological rearrangements, including alterations in the primary photosynthetic reactions (Guy et al. 2008). Plant development at highlight intensity and/or at low temperature leads to imbalance between the amount of absorbed light and capacity for its utilization causing overexcitation of the components of linear photosynthetic electron chain, usually expressed as excitation pressure $\left(1-\mathrm{q}_{\mathrm{P}}\right)$ that is reflecting redox state of the intersystem PQ pool (Huner et al. 1996, 1998).

Absorbing sunlight that prevails the demands of plants for effective photosynthetic process can potentially lead not only to excess excitation but also to generation of dangerous reactive oxygen species (ROS) that can cause photoinhibition of PSII (Aro et al. 1993, Long et al. 1994) and PSI (Sonoike et al. 1997, Ivanov et al. 1998). Under combined action of high-light illumination and low temperatures, the level of excitation pressure and oxidative stress is higher than the effect of only high light as the effectiveness of enzymatic reactions, especially of $\mathrm{CO}_{2}$ fixation, the main metabolic sink via $\mathrm{CO}_{2}$ reduction through the Calvin cycle, and photorespiration, are retarded (Allen and Ort 2001). For various types of photosynthetic organisms is of a great importance to sense the redox state of the photosynthetic electron chain and to apply different mechanisms to control the overaccumulation of redox intermediates under different environmental stress conditions and generation of ROS (Huner et al. 2013).

It is generally considered that the main mechanism of photoprotection in photosynthetic membranes of cyanobacteria, algae, and higher plants is operating in LHCII, is triggered by the build-up of $\mathrm{pH}$ gradient across the thylakoid membrane, and is a result from functioning of the xanthophyll cycle (NPQ) (Demmig-Adams and Adams 1992, Horton et al. 1996). However, there are indications that NPQ dissipates only part of the excessively absorbed light energy (Gilmore 1997). Important component of NPQ, which is involved in deexcitation of excited states of chlorophyll $(\mathrm{Chl})$ and thermal dissipation of excess light in LHCII, is $\mathrm{q}_{\mathrm{E}}$ that is dependent on $\Delta \mathrm{pH}$ and is rapidly reversible, considered to recover in several minutes after switching off the actinic light. It is induced by low values of $\mathrm{pH}$ in the thylakoid lumen (Müller et al. 2001, Ruban 2016). Arabidopsis thaliana mutants, npql (unable to convert violaxanthin to zeaxanthin; Niyogi et al. 1998) and lut2 (does not synthesize lutein or $\alpha$-carotene; Pogson et al. 1996), are characterized by diminished levels of $\mathrm{q}_{\mathrm{E}}$ (Niyogi et al. 1998, Pogson et al. 1998). In addition, it has been proposed that lutein also might have a direct role in $\mathrm{q}_{\mathrm{E}}$ formation (Niyogi et al. 1997, Lokstein et al. 2002).

Other mechanisms for protection against high light have been also reported, including decrease of functional absorption cross-section of PSII or of physical size of LHCII, transfer of energy by phosphorylated LHCII from PSII to PSI (state transition) (Huner et al. 1996, Ensminger et al. 2006), quenching excess light in the reaction center of PSII via the charge recombination between $\mathrm{P}_{680}{ }^{+}$and reduced Q $\mathrm{Q}_{\mathrm{A}}$ (Krieger et al. 1992, Ivanov et al. 2008). Under conditions of overexcitation of PSII, cyclic electron flow (CEF) around PSI provides electrons for synthesis of ATP at the acceptor side of PSI (Miyake et al. 2005, Wei et al. 2017, and references therein). In addition, part of the excess absorbed light can be diverted to harmless heat via mechanism that is not dependent on the functioning of the xanthophyll cycle in the antenna - nonregulated energy dissipation $\left(\Phi_{\mathrm{f}, \mathrm{D}}\right)$ (Hendrickson et al. 2004, Kramer et al. 2004, Ivanov et al. 2012). Another mechanism for increasing photochemical quenching has been reported in cold-acclimated cereals that respond to increased excitation pressure by elevated ribulose 1,5-bisphosphate regeneration and diverting the electron flow through the Calvin cycle for increase of $\mathrm{CO}_{2}$ fixation (Huner et al. 1998). All these photoprotective mechanisms act either separately or in different combinations to attain a proper balance between absorbed light and capacity of different metabolic sinks (Huner et al. 1998, 2013).

Xanthophylls are an intrinsic component of the photosynthetic machinery of higher plants which are attached to light-harvesting proteins of the main light-harvesting complexes of PSII, LHCII, via hydrophobic, van-der-Waals forces, and formation of $\mathrm{H}$-bonds with amino-acid side chains (Liu et al. 2004). In higher plants, two molecules of lutein and one molecule of violaxanthin and neoxanthin are bound to every monomer of the major trimeric complex of LHCII. The proper stoichiometry between these three xanthophylls and binding to their specific binding site determine the proper folding and organization of threedimensional structure of LHCII (Jahns and Holzwarth 2012). The missing xanthophylls can be substituted by other xanthophyll species but the resulting structure of LHCII is compromised (Croce et al. 1999). For the carotenoid mutant lut2 and lut1 of Arabidopsis thaliana, which do not contain lutein, it has been shown that the missing lutein is countervailed by increased content of other xanthophylls from the branch of $\beta$-carotene synthesis from lycopene (Pogson et al. 1996) and this substitution did not compromise the light-harvesting functions (Pogson et al. 1996, Lokstein et al. 2002, Dall'Osto et al. 2006) but the formation of stable trimers of LHCII was hampered (Lokstein et al. 2002) and the effectiveness of NPQ was much lower than that in wt (Dall'Osto et al. 2007). Additionally, mutants of Arabidopsis that lack lutein, growing under high light and/or low temperature, showed higher level of photodamage (Dall'Osto et al. 2006).

In addition, another function was attributed to lutein the quenching of the triplet excited states of Chl that have been shown in isolated and recombinant LHCII (Peterman et al. 1995, Croce et al. 1999). When lutein was missing, the degree of photobleaching of photosynthetic pigments in isolated thylakoid membranes was accelerated (Dobrev et al. 2016) supporting the suggestion that lutein performs an important role in effective quenching of ROS (Huang et al. 2010), in photoprotection, and prevention of LHCII proteins degradation under high-light illumination (Dall'Osto et al. 2006, Jahns and Holzwarth 2012). Indeed, mutants of Arabidopsis and Chlamydomonas that lack lutein and/or zeaxanthin are more photosensitive than the respective wt, but lutein alone is not able to provide effective photoprotection (Dall'Osto et al. 2007). Contrary, it has been also shown that the lack of lutein in Arabidopsis thaliana (Pogson et al. 1996) and 
Chlamydomonas reinhardtii (Niyogi et al. 1997) mutants does not significantly impact the photosynthetic process and its structural role in organization of LHCII can be fulfilled by the substituting xanthophylls.

Various economically important crop plans (wheat, tomato, etc.) could be frequently exposed to sudden periods of low temperatures during early spring and early fall in the temperate zone of the Northern hemisphere, when the light intensity is already/still high. The combination of these two factors can cause serious damage of the photosynthetic apparatus and loss of crop yield. The mechanisms allowing the plants to survive and recover from these harsh periods of low temperatures/high light are not well understood yet. The objective of the present study was to investigate the response of Arabidopsis thaliana plants, wt (Col-0) and lut2 mutant, lacking lutein, the most abundant xanthophyll, to combined treatment with two stress stimuli, low temperature $\left(12 / 10^{\circ} \mathrm{C}\right)$ and high light [500 $\mu$ mol(photon) $\mathrm{m}^{-2} \mathrm{~s}^{-1}$, in respect to photochemical activity of PSII and PSI in vivo and to follow the ability to recover after exposure to combined stress factors. Special attention was paid to energy partitioning and the role of alternative protective energy sinks as nonregulated thermal dissipation and CEF around PSI.

\section{Materials and methods}

Plant growth conditions: Plants of Arabidopsis thaliana, wt (Col-0) and mutant lut2, were grown in growth chambers (Fytoscope FS130, Photon Systems Instruments, Drásov, Czech Republic) under controlled conditions on perlite-containing soil. The photoperiod during the whole experimental setup was $12 \mathrm{~h}$. Light illumination during plant development was $100 \mu \mathrm{mol}$ (photon) $\mathrm{m}^{-2} \mathrm{~s}^{-1}$, day/ night temperature of $20 / 18^{\circ} \mathrm{C}$, and humidity of $70 \%$. Fully developed plants (after 3-4 weeks of growth) were further grown for $6 \mathrm{~d}$ at low day/night temperature $\left(12 / 10^{\circ} \mathrm{C}\right)$ and high light $\left[500 \mu \mathrm{mol}\left(\right.\right.$ photon) $\mathrm{m}^{-2} \mathrm{~s}^{-1}$. After 6 -d exposure to double stress conditions, plants were transferred back to growth conditions and were recovered for period of $7 \mathrm{~d}(7 \mathrm{R})$. Leaf samples were taken before the start of stress treatment $(0 \mathrm{~d})$, after 2 - and 6-d exposure and after $7-d$ recovery period. Five independent experiments were performed and at each timepoint, at least four parallel samples were processed. For all experiments leaves of fully developed plants were used.

Photosynthetic pigment content: Photosynthetic pigments were extracted from leaf material $(40 \mathrm{mg})$ with ice cold $80 \%$ acetone $(\mathrm{v} / \mathrm{v})$ in dim light as described in Gerganova et al. (2016). Leaf material was grinded at $4^{\circ} \mathrm{C}$ and the extracts were centrifuged in sealed tubes at $4,500 \times g$ for $15 \mathrm{~min}$ at $4^{\circ} \mathrm{C}$. The pigment content was determined spectrophotometrically (UV-VIS Specord 210 Plus, Analytic Jena, Jena, Germany) in the clear extract. Content of Chl $a$, Chl $b$, and carotenoids (Car) was determined according to Lichtenthaler (1987). At every timepoint, four parallel samples were collected from wt and lut 2 plants at the beginning of every experiment, after 2- or 6-d treatment of plants with low temperature and high light and after the recovery period at growth conditions. Mean values $\pm \mathrm{SE}$ were calculated from five independent experiments and expressed as $\mathrm{mg}$ (pigment) $\mathrm{g}^{-1}(\mathrm{FM})$.

Photosynthetic $\mathrm{CO}_{2}$ exchange: $\mathrm{CO}_{2}$ and water vapor exchange were measured with infrared gas analyzer LI-6262 ( $\mathrm{Li}$-Cor, USA) at $25^{\circ} \mathrm{C}$ and light intensity of $800 \mu$ mol(photon) $\mathrm{m}^{-2} \mathrm{~s}^{-1}$. The measurements were performed on intact leaves of control $(0 \mathrm{~d})$, treated $(6 \mathrm{~d})$, and recovered $(7 \mathrm{R}) \mathrm{wt}$ and lut 2 plants after $10-15 \mathrm{~min}$ to achieve steady-state conditions. The leaf was clamped in a gas-exchange cuvette at a rate of $0.75 \mathrm{~L} \mathrm{~min}^{-1}$ of air flow. The net rate of photosynthesis and the transpiration rate were calculated according to von Caemmerer and Farquhar (1981). The water-use efficiency (WUE) was calculated as a ratio between net rate of photosynthesis and transpiration rate.

Photosynthetic $\mathbf{O}_{2}$ evolution: The rate of net photosynthetic $\mathrm{O}_{2}$ evolution in leaves of Arabidopsis thaliana plants, wt and lut2, was determined by Clark-type $\mathrm{O}_{2}$ electrode (DW1, Hansatech Instruments, King's Lynn, Norfolk, UK) equipped with $L D 1 / 2$ leaf-disc electrode chamber as described in detail previously (Gray et al. 1996, Popova et al. 2019). Every measurement was performed on eight leaf discs with a total area of $10 \mathrm{~cm}^{2}$ in saturating atmosphere of $\mathrm{CO}_{2}$, provided by $200 \mu \mathrm{L}$ of $1 \mathrm{M} \mathrm{NaHCO}_{3}$. Measurements were performed before start of every experiment $(0 \mathrm{~d})$, after treatment with two stress factors for 2 and $6 \mathrm{~d}$, and after recovery for $7 \mathrm{~d}$. At every timepoint, at least four parallel samples were measured. Every sample was dark-adapted for $5 \mathrm{~min}$ at room temperature $\left(22^{\circ} \mathrm{C}\right)$. Light-response curves of leaf discs were created by plotting the evolved $\mathrm{O}_{2}$ against respective light intensity from 0 to $1,400 \mu \mathrm{mol}$ (photon) $\mathrm{m}^{-2} \mathrm{~s}^{-1}$ provided by an array of red light-emitting $(650 \mathrm{~nm})$ diodes (LH36/2R, Hansatech Instruments Ltd., King's Lynn, Norfolk, UK). The rate of $\mathrm{O}_{2}$ evolution at every light intensity was corrected for the level of dark respiration. Light-compensation points (LCP) were registered as in Bravo et al. (2007). LCP is the point where the light-response curve intercepts the line parallel to the $\mathrm{x}$ coordinate at 0 value of oxygen evolution $\left(\mathrm{P}_{\mathrm{m}}\right)$.

Pulse-Amplitude-Modulated chlorophyll $a$ fluorescence: Parameters of PSII photosynthetic performance were determined on dark-adapted leaves for $15 \mathrm{~min}$ in wt and lut 2 fully developed plants - control, nontreated plants, treated with two stress stimuli for 2 or $6 \mathrm{~d}$ and after recovery period of $7 \mathrm{~d}$. Measurements were performed at room $\left(22^{\circ} \mathrm{C}\right)$ temperature and ambient $\mathrm{CO}_{2}$ and $\mathrm{O}_{2}$ conditions using PAM-101/103 fluorometer (Heinz Walz $\mathrm{GmbH}$, Effeltrich, Germany) as described previously (Popova et al. 2019). The minimal Chl fluorescence when all PSII centers were open $\left(\mathrm{F}_{0}\right)$ was registered at illumination with weak $\left[0.120 \mu \mathrm{mol}\right.$ (photon) $\left.\mathrm{m}^{-2} \mathrm{~s}^{-1}\right]$ modulated $(1.6 \mathrm{kHz})$ light. A white-light pulse with saturating intensity of $3,000 \mu \mathrm{mol}$ (photon) $\mathrm{m}^{-2} \mathrm{~s}^{-1}$ and duration of $0.8 \mathrm{~s}$ was applied to close all PSII and to register the maximal fluorescence $\mathrm{F}_{\mathrm{m}}$. To initiate photosynthetic process, leaf sample was illuminated for $5 \mathrm{~min}$ with actinic 
light that corresponded to plant growth illumination [100 $\mu \mathrm{mol}\left(\right.$ photon) $\left.\mathrm{m}^{-2} \mathrm{~s}^{-1}\right]$ and saturating light pulse was given every minute to determine the maximal fluorescence level in the light-adapted state $\left(\mathrm{F}_{\mathrm{m}}{ }^{\prime}\right)$. After reaching the steady-state fluorescence level $\left(\mathrm{F}_{\mathrm{s}}\right)$, the actinic light was switched off and the minimal fluorescence in the lightadapted state $\left(\mathrm{F}_{0}{ }^{\prime}\right)$ was registered. After switching off the actinic light, saturating pulses of white light were given every $10 \mathrm{~s}$ for $1 \mathrm{~min}$ followed by pulses every $30 \mathrm{~s}$ for registration of the rapidly reversible component of NPQ, $\mathrm{q}_{\mathrm{E}}$ (Ivanov et al. 2006, Ruban 2016). The main photosynthetic parameters of PSII activity were calculated using formulas of van Kooten and Snel (1990). Maximal quantum yield of PSII in the dark-adapted state was determined as $\mathrm{F}_{\mathrm{v}} / \mathrm{F}_{\mathrm{m}}=$ $\left(\mathrm{F}_{\mathrm{m}}-\mathrm{F}_{0}\right) / \mathrm{F}_{\mathrm{m}}$, excitation pressure of PSII as $1-\mathrm{q}_{\mathrm{P}}=$ $1-\left[\left(F_{m}{ }^{\prime}-F_{s}\right) /\left(F_{m}{ }^{\prime}-F_{0}{ }^{\prime}\right)\right]$. The quantum efficiency of $\Delta \mathrm{pH}$ - and/or xanthophylls-dependent nonphotochemical quenching of excess absorbed light in PSII antennae as $\Phi_{\mathrm{NPQ}}=\mathrm{F}_{\mathrm{s}} / \mathrm{F}_{\mathrm{m}}{ }^{\prime}-\mathrm{F}_{\mathrm{s}} / \mathrm{F}_{\mathrm{m}}$, and actual photochemical efficiency of PSII as $\Phi_{\text {PSII }}=\left(F_{m}{ }^{\prime}-F_{s}\right) / F_{m}{ }^{\prime}$. Constitutive energy dissipation was calculated as $\Phi_{\mathrm{f}, \mathrm{D}}=\mathrm{F}_{\mathrm{s}} / \mathrm{F}_{\mathrm{m}}$ (Hendrickson et al. 2004, Ivanov et al. 2012).

Redox state of $\mathbf{P}_{700}$ : Alterations in the redox state of $\mathbf{P}_{700}$ were registered in leaves of wt and lut2 plants, dark-adapted for $15 \mathrm{~min}$, before the start of every experiment, after 2- or 6-d exposure to stress conditions and after recovery period of $7 \mathrm{~d}$ using a $P A M-101 / 103$ modulated fluorometer (Heinz Walz GmbH, Effeltrich, Germany) equipped with ED-800T emitter-detector unit (Klughammer and Schreiber 1991) as described in Ivanov et al. (1998). Measurements were performed at $22^{\circ} \mathrm{C}$ and ambient $\mathrm{O}_{2}$ and $\mathrm{CO}_{2}$ conditions. Leaves were illuminated with farred light $\left(\lambda_{\max }=715 \mathrm{~nm}, 10 \mathrm{~W} \mathrm{~m}^{-2}\right.$, Schott filter $\left.R G 715\right)$. The redox state of $\mathrm{P}_{700}$ was registered as FR-induced absorbance change around $820 \mathrm{~nm}\left(\Delta \mathrm{A}_{820}\right)$ in a customdesigned cuvette. Multiple-turnover (MT, $50 \mathrm{~ms}$ ) and single-turnover (ST, half peak $14 \mu \mathrm{s}$ ) saturating flashes were applied by XMT-103 and XST-103 (Walz) power/ control units, respectively. The relative functional pool size of the intersystem electrons able to reduce PSI center $\left(\mathrm{P}_{700}{ }^{+}\right)$was calculated as the ratio between the area of MT to the area of ST flashes $\left(\mathrm{e}^{-} / \mathrm{P}_{700}=\mathrm{MT}\right.$ area/ST area) (Asada et al. 1993, Ivanov et al. 1998).

The half time $\left(t_{1 / 2}\right)$ of the decay kinetics of re-reduction of $\mathrm{P}_{700}{ }^{+}$after switching off FR illumination was assessed as the capacity for CEF around PSI (Klughammer and Schreiber 1991, Ivanov at al. 1998).

Electrolyte leakage: Electrolyte leakage from leaf tissue $(150 \mathrm{mg})$ was measured with a conductivity meter (EC 215, Hanna Instruments, USA) after 24-h incubation of leaf discs in double-distilled water $(15 \mathrm{ml})$. The conductivity of the floating solution was measured after 24-h shaking and the maximum leakage of the tissue was determined after boiling the leaves for $15 \mathrm{~min}$ at $100^{\circ} \mathrm{C}$. The extent of leakage was presented as percentage of the maximum leakage.

Statistics: Data were presented as mean values $\pm \mathrm{SE}$, calculated from five independent experiments with four parallel samples for each time point. Statistically significant differences were calculated by two-tail Student's $t$-test in Excel. Statistical differences between values of wt and lut 2 plants were indicated with $(+)$ and between values of nontreated and treated leaves with $(*),(+/ * P<0.05$; $++/ * * P<0.01 ;+++/ * * * P<0.001)$.

\section{Results}

Photosynthetic pigments and electrolyte leakage: The content of photosynthetic pigments in wt and lut 2 leaves of control and plants treated by low temperature and high light for 2 and $6 \mathrm{~d}$ and after recovery did not differ significantly between control wt and lut 2 plants, although in nontreated lut 2 plants, the content of $\mathrm{Chl} a, \mathrm{Chl} b$, and total carotenoids was slightly lower (around 10\%) than that in wt (Table 1S, supplement). After development at these conditions for $6 \mathrm{~d}$, a significant reduction of all photosynthetic pigments took place, the effect being stronger in lut 2 mutant compared to wt (Table 1S). Further development at original growth conditions for $7 \mathrm{~d}$ did not lead to complete recovery of pigment contents to that of nontreated plants.

The membrane integrity was assessed by measuring the extent of electrolyte leakage. Electrolyte leakage of control, nontreated leaves of wt and lut 2 plants was similar, $18.3 \pm 0.8 \%$ and $18.1 \pm 1.2 \%$, respectively. After $6 \mathrm{~d}$ of combined treatment, the values of this parameter increased to $25.4 \pm 9.2 \%$ and $20.9 \pm 1.3 \%$ for wt and lut2 leaves, respectively, indicating some destabilization of the membranes under these conditions. However, this enhancement in electrolyte leakage was reversible and it strongly declined after recovery of plants (Fig. 1).

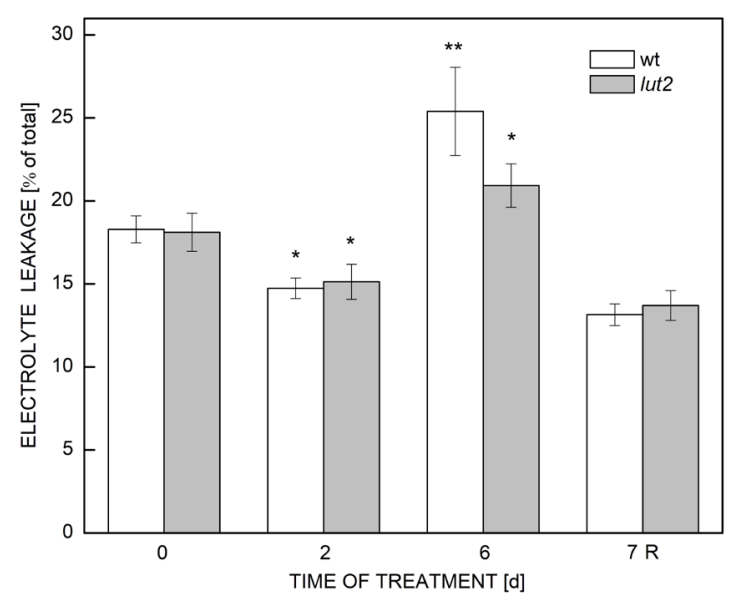

Fig. 1. Effect of combined treatment for 2 and $6 \mathrm{~d}$ with low temperature $\left(12 / 10^{\circ} \mathrm{C}\right)$ and high light $\left[500 \mu \operatorname{mol}\left(\right.\right.$ photon) $\left.\mathrm{m}^{-2} \mathrm{~s}^{-1}\right]$ and after recovery period of $7 \mathrm{~d}(7 \mathrm{R})$ of Arabidopsis plants, wt and lut2, on electrolyte leakage. Means $\pm \mathrm{SE}$ values were calculated from five independent experiments with at least four parallel samples $(n=20)$. Statistically significant differences were calculated by two-tail Student's $t$-test. Statistical differences between values of wt and lut 2 plants were indicated with $(+)$ and differences between respective control and treated plants with $(*) .(+/ * P<0.05 ;++/ * * P<0.01 ;+++/ * * * P<0.001)$. 
$\mathrm{CO}_{2}$ fixation and oxygen evolution of leaves: The net rate of photosynthesis (Fig. 2A) in control, nontreated wt plants was about $20 \%$ higher than that in lut 2 plants. After treatment for $6 \mathrm{~d}$, the net rate of photosynthesis in wt plants decreased by $30 \%$ and by only $7 \%$ in lut 2 plants in comparison with nontreated plants. After recovery period, the values showed complete recovery for wt plants while for $l u t 2$, the values were even higher than before the start of the treatment. Similar alterations after $6 \mathrm{~d}$ of treatment were observed for the transpiration rates (Fig. $2 B$ ). The observed stress-induced decline in the water-use efficiency (WUE) was less evident and wt and lut 2 plants responded to the stress conditions in a similar manner (data not shown).

Light-response curves of photosynthetic oxygen evolution of wt (Fig. 3A) and lut2 (Fig. 3B) leaves are presented in Fig. 3. For both types of leaves, the rate of oxygen evolution at low light intensity increased linearly till reaching a plateau at $250 \mu \mathrm{mol}$ (photon) $\mathrm{m}^{-2} \mathrm{~s}^{-1}$. For

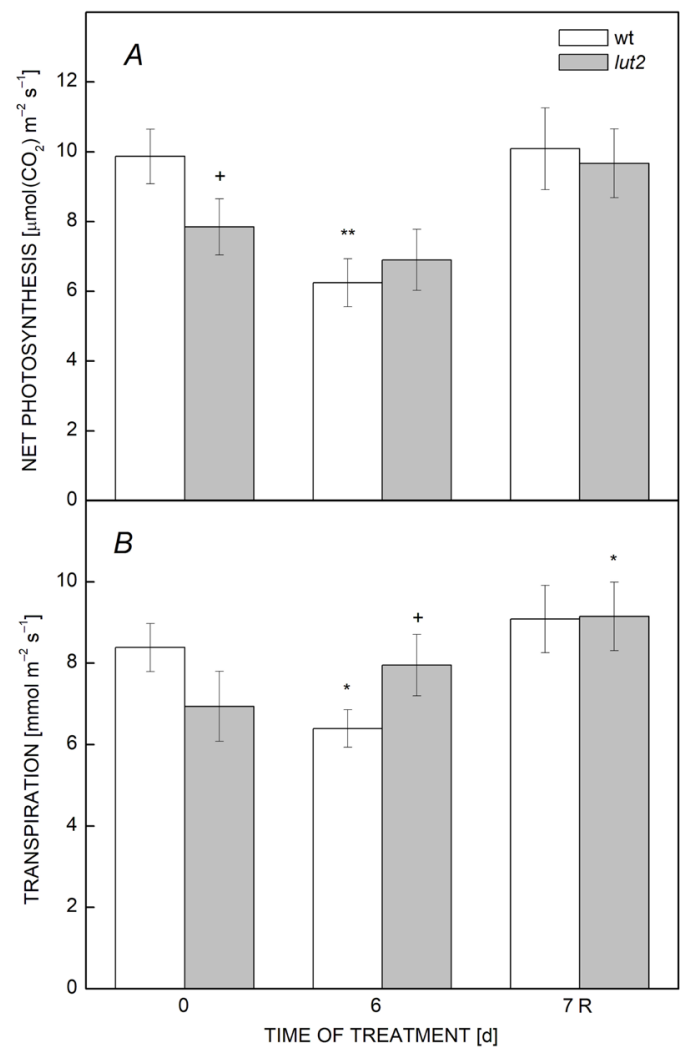

Fig. 2. Effect of combined treatment with low temperature $\left(12 / 10^{\circ} \mathrm{C}\right)$ and high-light illumination $\left[500 \mu \mathrm{mol}\right.$ (photon) $\left.\mathrm{m}^{-2} \mathrm{~s}^{-1}\right]$ of Arabidopsis plants, wt and lut 2 mutant, on the net rate of photosynthesis $(A)$ and transpiration rate $(B)$. Presented values were registered in intact nontreated, treated for $6 \mathrm{~d}$, and after a recovery period of $7 \mathrm{~d}(7 \mathrm{R})$ plants. Means \pm SE values were calculated from five independent experiments with at least two parallel samples $(n=10)$. Statistically significant differences were calculated by two-tail Student's $t$-test. Statistical differences between values of wt and lut 2 plants were indicated with $(+)$ and differences between respective control and treated plants with $(*) .(+/ * P<0.05 ;++/ * * P<0.01 ;+++/ * * * P<0.001)$. both types of leaves, the prolonged treatment with two stress factors caused a decrease in saturating level of oxygen evolution $\left(P_{\mathrm{Nmax}}\right)$. For wt plants, the decrease after 2 or $6 \mathrm{~d}$ of treatment was 6 and $17 \%$, respectively, while for lut 2 plants, the decrease of $P_{\mathrm{Nmax}}$ was 20 and $23 \%$, respectively. After recovery period, a complete restoration of oxygen evolution was obtained, reaching values around $15 \%$ higher than that in respective nontreated plants.

Light-compensation points (LCP) of wt and lut2 leaves were also determined from the light-response curves presented in Fig. 3. Untreated leaves of wt exhibited LCP of $33 \mu \mathrm{mol}$ (photon) $\mathrm{m}^{-2} \mathrm{~s}^{-1}$ while for lut 2 leaves the value of LCP was $40 \%$ higher $\left[47 \mu \mathrm{mol}\right.$ (photon) $\mathrm{m}^{-2} \mathrm{~s}^{-1}$, thus indicating a higher respiration rate in lut 2 mutant. Exposure of both wt and lut 2 to combined treatment with two stress factors for 2 and 6 d resulted in two-fold higher

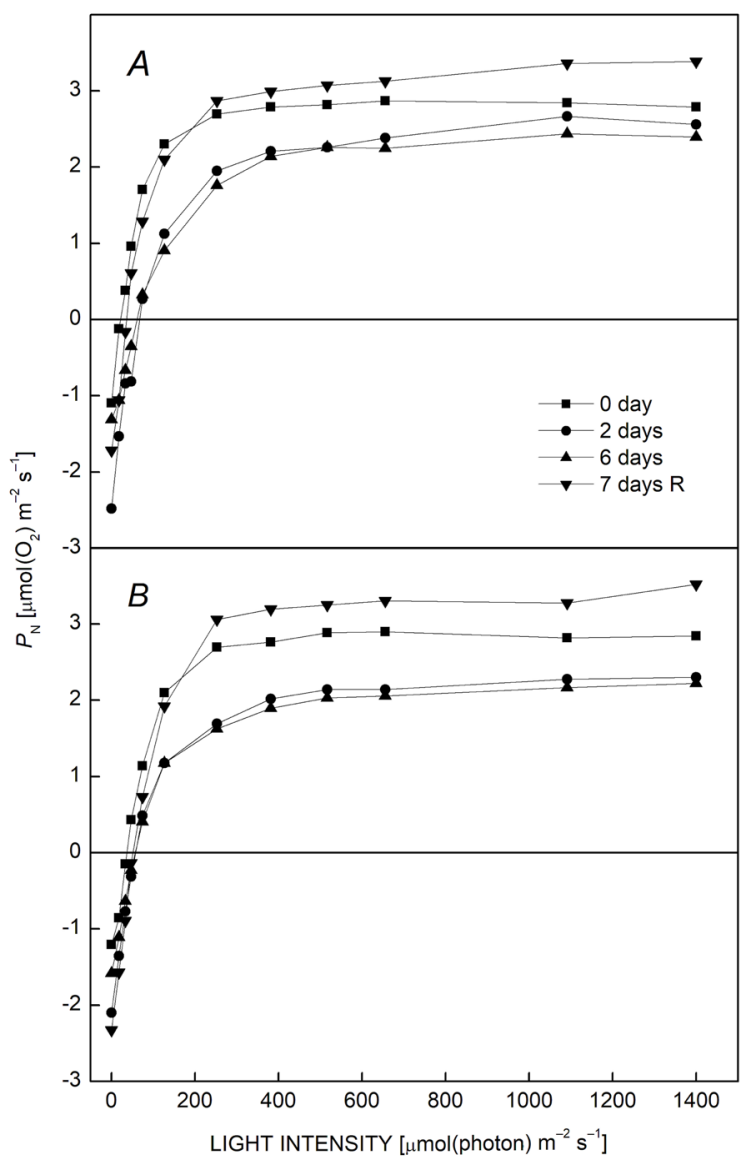

Fig. 3. Oxygen-evolving activity of leaf discs of Arabidopsis plants, wt $(A)$ and lut 2 mutant $(B)$, at increasing light intensity [0 to $1,400 \mu \mathrm{mol}\left(\right.$ photon) $\mathrm{m}^{-2} \mathrm{~s}^{-1}$ ], provided by an array of red-light emitting diodes $(650 \mathrm{~nm})$. Leaf discs were taken from mature plants at the beginning of every experiment ( 0 day), after 2 or $6 \mathrm{~d}$ at combined treatment with two stress factors and after recovery period (7-d R). Oxygen evolution was registered at room temperature $\left(22^{\circ} \mathrm{C}\right)$ in a $\mathrm{CO}_{2}$ saturating atmosphere. Every sample contained eight leaf discs. Mean values for every light response curve were calculated from two independent experiments with three parallel samples $(n=6)$. 
LCP values [74 $\mu \mathrm{mol}$ (photon) $\mathrm{m}^{-2} \mathrm{~s}^{-1}$ ] compared to control plants. Transfer of plants back to growth conditions for their recovery decreased significantly the values of LCP [47 $\mu \mathrm{mol}$ (photon) $\mathrm{m}^{-2} \mathrm{~s}^{-1}$ ] but they were still higher than that in nontreated plants.

Photosynthetic performance of PSII: The maximal quantum yield of PSII $\left(\mathrm{F}_{\mathrm{v}} / \mathrm{F}_{\mathrm{m}}\right)$ was reduced in both types of plants to a similar extent after 2 and $6 \mathrm{~d}$ of combined stress treatment and fully recovered after $7 \mathrm{~d}$ of growth under control conditions (Fig. $4 A$ ). The quantum efficiency of PSII $\left(\Phi_{\text {PSII }}\right)$ in both wt and lut 2 mutant (Fig. 1S, supplement) decreased similarly after $2 \mathrm{~d}$ of treatment but at longer exposure, the values for both types of leaves were higher than on the second day and mutant plants recovered more efficiently from stress.

Nontreated wt and lut 2 plants exhibited comparable $1-\mathrm{q}_{\mathrm{P}}$ values. As expected, $1-\mathrm{q}_{\mathrm{P}}$ values strongly increased with duration of the combined stress treatment (Fig. 4B). This increase was similar after 2 and $6 \mathrm{~d}$ of treatment in wt plants (with 58 and $56 \%$, respectively), while the elevation of this parameter for lut 2 plants was gradual and smaller
(23 and 32\%), respectively. These alterations were fully reversible and after return of plants to growth conditions the values of $1-\mathrm{q}_{\mathrm{P}}$ were comparable with those before treatment.

In Fig. $4 C$, values of the estimated quantum efficiency of NPQ $\left(\Phi_{\mathrm{NPQ}}\right)$ are shown. The value of nontreated lut 2 plants was much lower (35\%) than that of nontreated wt plants. Exposure of wt and lut 2 plants to the combined stress caused a strong reduction of $\Phi_{\mathrm{NPQ}}$, the effect being more pronounced in lut 2 . For wt leaves, the decline was 25 and $55 \%$ after 2 and $6 \mathrm{~d}$ of combined treatment, respectively, compared to nontreated plants. For leaves of lut 2 plants, the decrease in $\Phi_{\mathrm{NPQ}}$ was much stronger, with 50 and $60 \%$, after 2 and $6 \mathrm{~d}$ of treatment, respectively. After a recovery period, the level of $\Phi_{\mathrm{NPQ}}$ in wt leaves remained comparable with that after treatment for $6 \mathrm{~d}$, while lut 2 leaves showed a complete recovery and the value of $\Phi_{\mathrm{NPQ}}$ was close to that in nontreated lut2 plants (Fig. 4C).

It is generally considered that the major component of NPQ is the $\Delta \mathrm{pH}$ - and energy-dependent quenching - $\mathrm{q}_{\mathrm{E}}$ (Horton et al. 1996, Ivanov et al. 2006, Ruban 2016). It is generated within several minutes of exposure to light

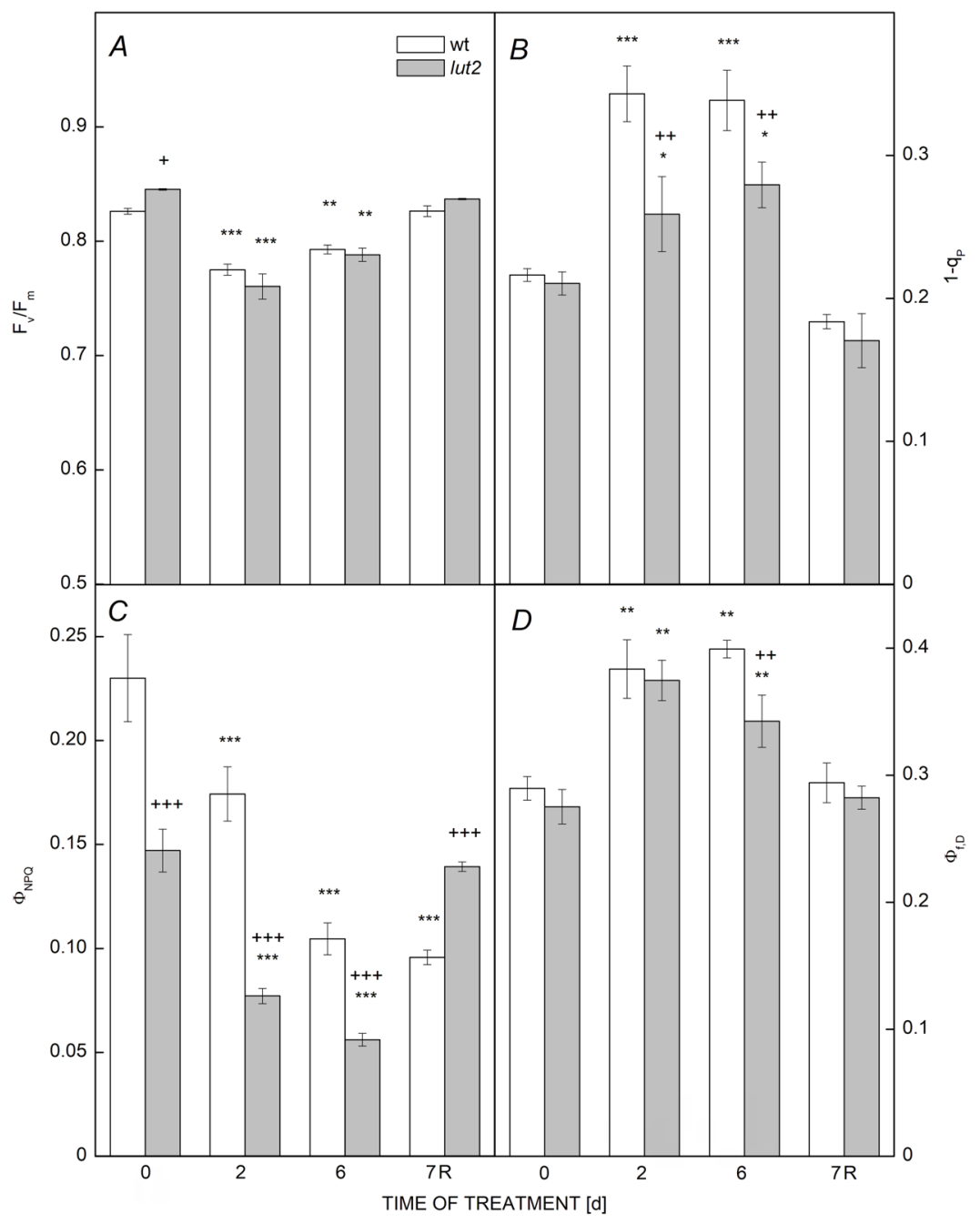

Fig. 4. Alterations in photosynthetic parameters of PSII as induced by combined treatment of Arabidopsis plants, wt and lut2, for 0,2 , and $6 \mathrm{~d}$, and after recovery $(7 \mathrm{R})$ at growth conditions. Maximal quantum yield of PSII, $\mathrm{F}_{\mathrm{v}} / \mathrm{F}_{\mathrm{m}}(A)$, excitation pressure, $1-\mathrm{q}_{\mathrm{p}}(B)$, quantum yield of the regulated energy dissipation of PSII, $\Phi_{\mathrm{NPQ}}(C)$, and efficiency of constitutive energy dissipation, $\Phi_{\mathrm{f}, \mathrm{D}}(D)$. Mean values \pm SE were calculated from at least three measured values for every time point in five independent experiments $(n=15)$. Statistically significant differences were calculated by two-tail Student's $t$-test. Statistical differences between values of wt and lut 2 plants were indicated with $(+)$ and differences between respective control and treated plants with $(*) .(+/ * P<0.05$; $++/ * * P<0.01 ;+++/ * * * P<0.001)$. 
and relaxes for up to $5 \mathrm{~min}$ in darkness (Horton et al. 1996, Ruban 2016). The initial fast phase of the recovery of $\mathrm{q}_{\mathrm{E}}$ was assessed in wt and lut 2 leaves after switching off the actinic light and application of saturating pulses (Fig. 5) with different time intervals. The recovery of Chl $a$ fluorescence flash yields was plotted against time (Fig. 6) to characterize the dynamics of relaxation of $\mathrm{q}_{\mathrm{E}}$ in both types of leaves. From Figs. 5 and 6 is evident that the extent of $\mathrm{q}_{\mathrm{E}}$ relaxation in the mutant, in nontreated, treated for 2 and $6 \mathrm{~d}$, and after recovery, was much lower than in $\mathrm{wt}$ for the whole measuring period $(4.5 \mathrm{~min})$. The initial slope of $\mathrm{q}_{\mathrm{E}}$ relaxation curves (Fig. 6) (an approximation for the rate of relaxation) was similar in wt and lut 2 leaves in both types of leaves, the rate of $\mathrm{q}_{\mathrm{E}}$ relaxation was faster before the start of experiment and after $2 \mathrm{~d}$ of treatment while for longer treatment $(6 \mathrm{~d})$ and after the recovery period, the kinetics of $\mathrm{q}_{\mathrm{E}}$ relaxation was significantly suppressed.

With prolonged treatment time, the values of $\Phi_{\mathrm{NPQ}}$ gradually decreased in wt and lut2 plants (Fig. 4C). At the same time, the nonregulated energy dissipation $\left(\Phi_{\mathrm{f}, \mathrm{D}}\right)$ increased by $30 \%$ after 2 and $6 \mathrm{~d}$ of treatment in comparison with the respective control plants (Fig. 4D). After the end of treatment, during the recovery period, values of $\Phi_{\mathrm{f}, \mathrm{D}}$ showed complete recovery (Fig. $4 D$ ).
Redox state of PSI: The alterations in the redox state of PSI of wt and lut2 leaves as a result of stress treatment were assessed by following the FR-induced absorbance change at $820 \mathrm{~nm}\left(\Delta \mathrm{A}_{820}\right)$. The FR-induced oxidation of $\mathrm{P}_{700}\left(\mathrm{P}_{700}{ }^{+}\right)$was not changed in wt leaves in the course of treatment. In lut2 leaves, the level of $\mathrm{P}_{700}{ }^{+}$increased after $2 \mathrm{~d}$ and did not change significantly at a longer exposure to combined stress. The registered oxidation level of $\mathrm{P}_{700}$ $\left(\mathrm{P}_{700}{ }^{+}\right)$after the recovery period significantly increased by 40 and $50 \%$ for wt and lut 2 leaves, respectively (Fig. $7 A$ ).

In order to determine the apparent intersystem electron pool size that can be donated to PSI $\left(\mathrm{e}^{-} / \mathrm{P}_{700}\right)$ in vivo, single- and multiple-turnover flashes (ST and MT) of white light were given when steady-state oxidation level of $\mathrm{P}_{700}\left(\mathrm{P}_{700}{ }^{+}\right)$was reached. Results presented in Fig. $7 B$ indicated that the intersystem electron pool in nontreated wt and lut 2 plants were comparable. An exposure to combined stress resulted in a gradual increase of $\mathrm{e}^{-} / \mathrm{P}_{700}$ values, being stronger expressed in lut 2 leaves. For leaves of wt after transfer of plants to growth conditions, the $\mathrm{e}^{-} / \mathbf{P}_{700}$ restored to control value while for the mutant, the value decreased in comparison to $6^{\text {th }} \mathrm{d}$ of treatment but remained higher than the value of nontreated lut 2 plants.

After switching off the FR light, the half time of

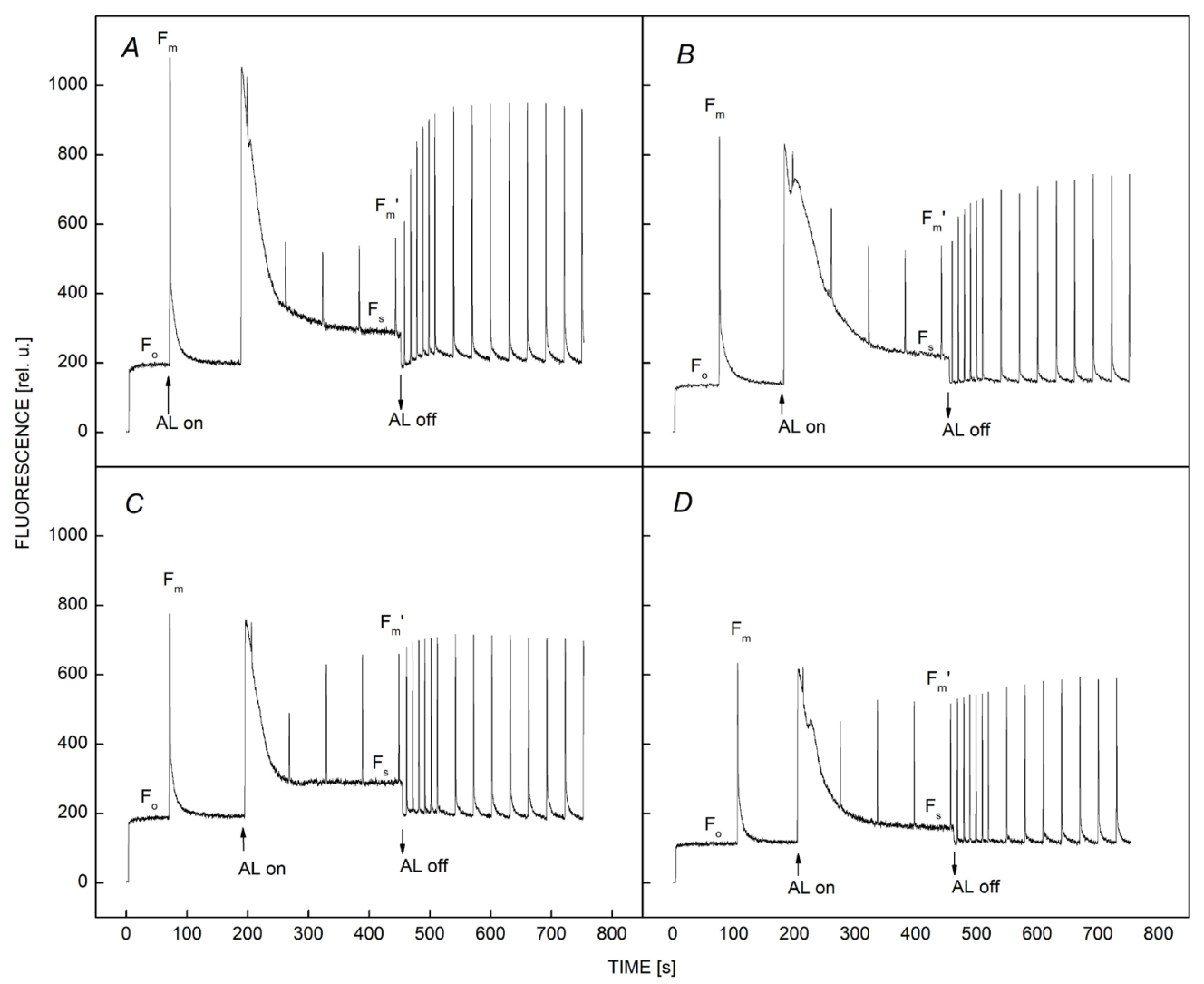

Fig. 5. Typical traces of chlorophyll $a$ fluorescence induction curves, before turning on actinic light (AL), after turning off AL, and series of saturating light pulses after the AL was switched off, of wt $(A, C)$ and of lut 2 leaves $(B, D)$ before start of experiment $(A, B)$ and after 6-d exposure to two stress factors $(C, D)$. The arrows indicate turning on and off $\mathrm{AL}\left[100 \mu \mathrm{mol}(\mathrm{photon}) \mathrm{m}^{-2} \mathrm{~s}^{-1}\right]$. After reaching a steadystate fluorescence $\left(\mathrm{F}_{\mathrm{s}}\right)$, the AL was turned off, $\mathrm{F}_{0}{ }^{\prime}$ was detected, and multiple saturating flashes were given to estimate the relaxation of energy-dependent component $\left(\mathrm{q}_{\mathrm{E}}\right)$ of nonphotochemical quenching (NPQ). 
the dark decay of oxidized to reduced state of $\mathrm{P}_{700}$ was determined as a measure of effectiveness of cyclic electron flow (CEF) $\left(\mathrm{t}_{1 / 2}\right)$ (Fig. 7C). Half time of reduction of $\mathrm{P}_{700}{ }^{+}\left(\mathrm{t}_{1 / 2}\right)$ in leaves of nontreated lut2 plants was $1.88 \pm 0.05 \mathrm{~s}$, lower than that in leaves of nontreated $\mathrm{wt}$ plants $(2.18 \pm 0.09 \mathrm{~s})$ suggesting that CEF was upregulated in lut2 compared to wt. In the course of treatment with two stress factors, the rates of $\mathrm{P}_{700}{ }^{+}$decay $\left(\mathrm{t}_{1 / 2}\right)$ were accelerated in both types of plants, stronger expressed in wt, suggesting a higher capacity for CEF under these stress conditions. After the recovery period of $7 \mathrm{~d}$, the values of $\mathrm{t}_{1 / 2}$ showed a complete recovery in both wt and lut 2 plants.

\section{Discussion}

The main challenge of higher plants developing under abiotic stress conditions, especially under high light and/or in combination with low temperature, is to maintain balance between quantity of absorbed light with temperature-

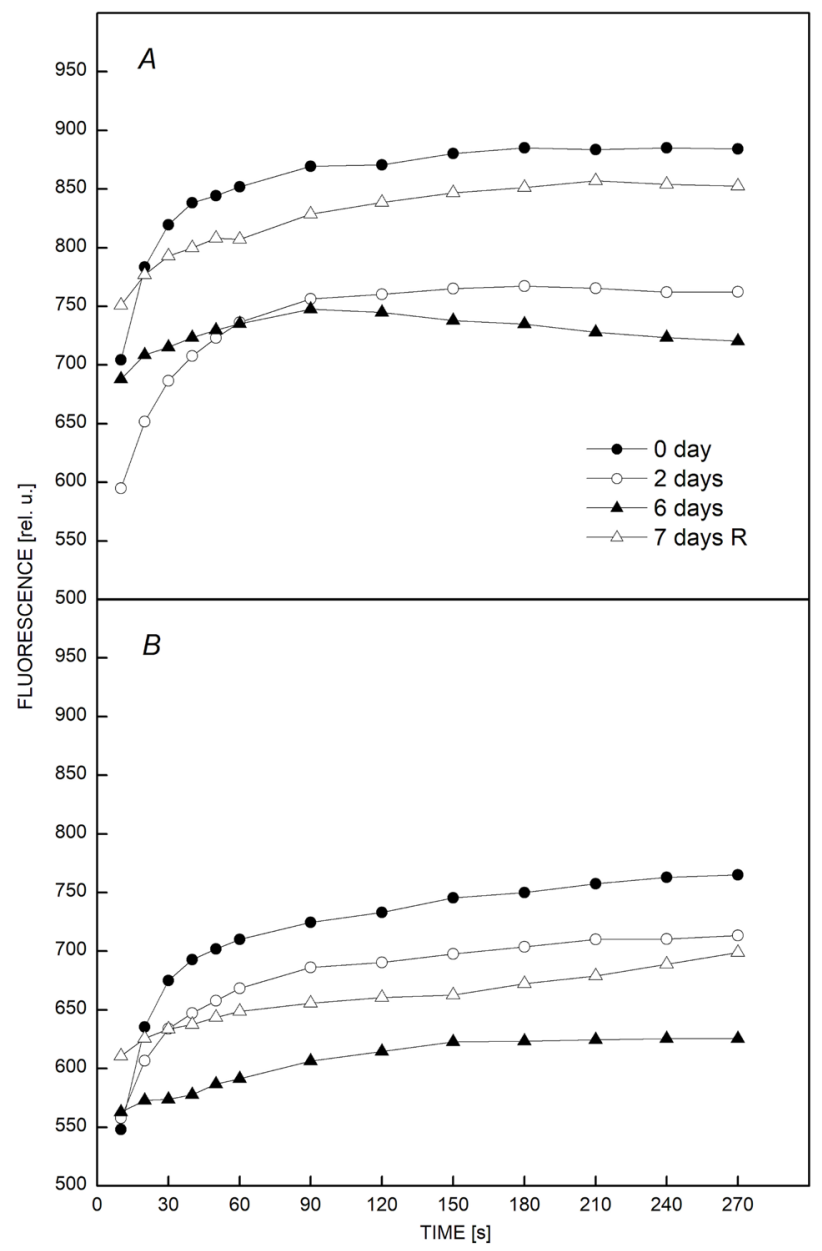

Fig. 6. Time-dependent relaxation of $\mathrm{q}_{\mathrm{E}}$ component of NPQ after turning off the actinic light and giving a set of saturating flashes of white light in leaves of Arabidopsis plants, wt $(A)$ and lut2 $(B)$, before start of every experiment, after 2- or 6-d treatment with two stress factors, and after recovery period of $7 \mathrm{~d}(7-\mathrm{d}$ R). Mean curves were calculated from at least three fluorescence traces. dependent metabolic reactions. Absorbing excess light can lead to excitation pressure on PSII $\left(1-\mathrm{q}_{\mathrm{P}}\right)$ (Huner et al. 1996, 1998) that can cause generation of ROS and consequently photoinhibition and/or photooxidative stress of PSII and PSI (Powles 1984, Aro et al. 1993).

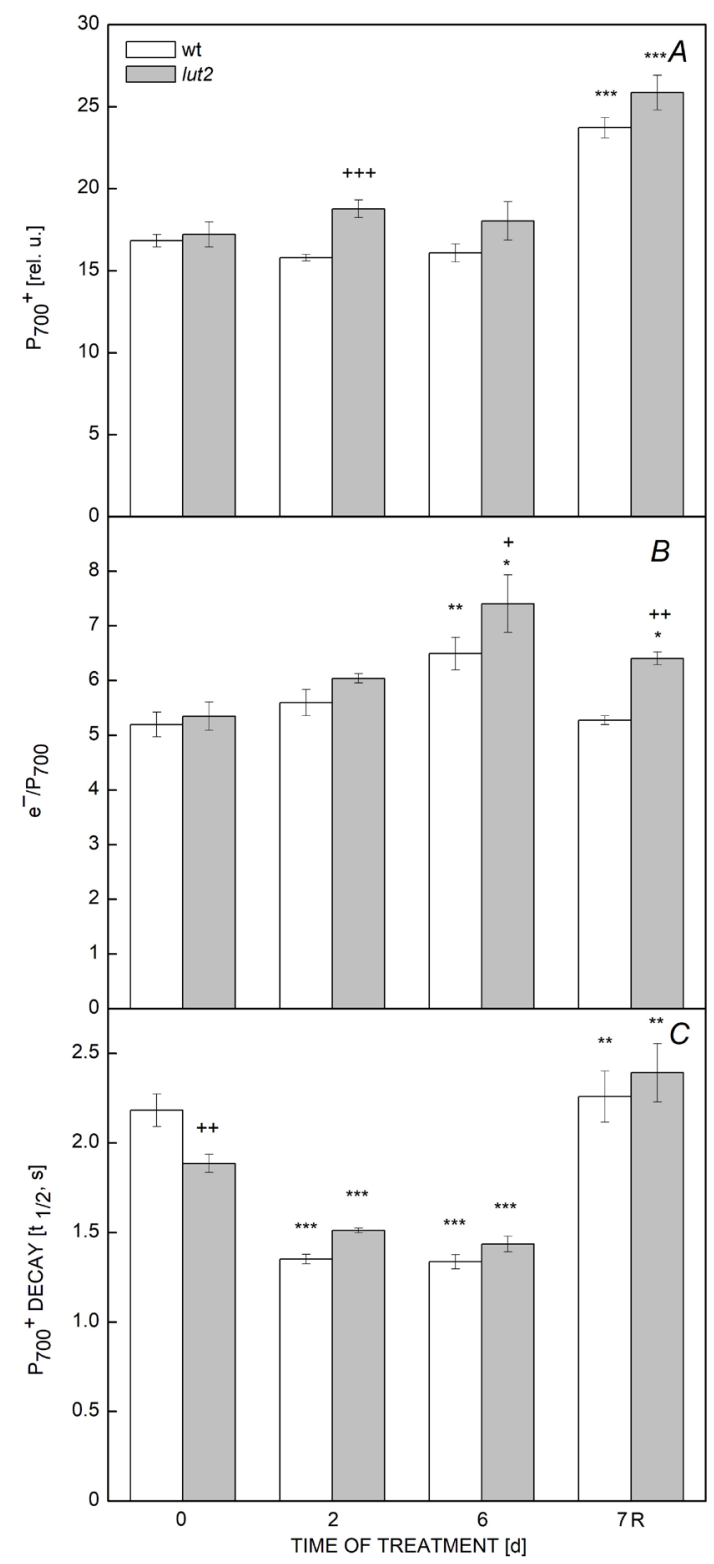

Fig. 7. Alterations in FR-induced oxidation of $\mathrm{P}_{700}(A)$, intersystem electron pool size $\left(\mathrm{e}^{-} / \mathrm{P}_{700}\right)(B)$, and $\mathrm{P}_{700}{ }^{+}$decay $\left(\mathrm{t}_{1 / 2}\right)$, related to efficiency of cyclic electron flow around PSI $(C)$. Measurements were performed on fully developed leaves of Arabidopsis plants, wt and lut2, treated with combined two stress factors for 0,2 , and $6 \mathrm{~d}$ and after recovery for $7 \mathrm{~d}(7 \mathrm{R})$. Mean values $\pm \mathrm{SE}$ were calculated from at least three measured values for every time point in five independent experiments $(n=15)$. Statistically significant differences were calculated by two-tail Student's $t$-test. Statistical differences between values of wt and lut 2 plants were indicated with $(+)$ and differences between respective control and treated plants with $(*) .(+/ * P<0.05 ;++/ * * P<0.01 ;+++/ * * * P<0.001)$. 
The exposure of wt and lut2 plants to two stress factors led to a comparable decrease of the maximal quantum yield of PSII $\left(\mathrm{F}_{\mathrm{v}} / \mathrm{F}_{\mathrm{m}}\right.$; Fig. $\left.4 A\right), \Phi_{\text {PSII }}$ (Fig. $\left.1 \mathrm{~S}\right)$, and the rates of oxygen evolution $\left(P_{\mathrm{Nmax}} ;\right.$ Fig. 3$)$. The almost equal decline of both parameters after 2 and $6 \mathrm{~d}$ correlated with an equal increase of dark respiration as suggested by the identical increase of LCPs in both wt and lut2 leaves. The observed moderate changes in these parameters (with around 20\%) were not surprising as the applied stress factors were not extreme and plants were able to recover successfully after period of $7 \mathrm{~d}$ at control conditions. Furthermore, the stability of cell membranes was not significantly compromised, as evidenced by an extent of electrolyte leakage. The observed decline in $\mathrm{F}_{\mathrm{v}} / \mathrm{F}_{\mathrm{m}}$ and oxygen evolution correlated with increased excitation pressure on PSII ( $1-\mathrm{q}_{\mathrm{P}}$ ) (Figs. 3, 4A,B). A similar increase of $1-\mathrm{q}_{\mathrm{P}}$ had been reported for Arabidopsis wt plants exposed to low temperature (Ivanov et al. 2012). However, the increase of $1-\mathrm{q}_{\mathrm{P}}$ in lut 2 leaves was significantly smaller compared to wt. Considering that the lack of lutein is compromising the formation of stable three-dimensional organization of LHCII (Dall'Osto et al. 2006), it is very likely that the lower antenna size of PSII prevents its over-reduction under the applied stress conditions.

Nonphotochemical quenching of excess light energy (NPQ) and especially of its energy-dependent component $\mathrm{q}_{\mathrm{E}}$ is generally considered to be the main photoprotective mechanism converting excess absorbed light into harmless heat and is the fastest response to a photoinhibitory treatment that is related to processes of light harvesting by photosynthetic antenna complexes, their structure, organization, stability, and pigment composition (DemmigAdams and Adams 1992, Horton et al. 1996, Ruban 2016). The registered value of $\Phi_{\mathrm{NPQ}}$ in nontreated lut 2 leaves was $37 \%$ lower than that in nontreated wt plants (Fig. 4C). As NPQ is largely dependent on the xanthophylls zeaxanthin and lutein (Pogson et al. 1998, Niyogi et al. 2001), it could be expected that the lack of lutein and the compromised structure and stability of LHCII in lut 2 could be the reason for the lower capacity of LHCII to perform its main photoprotective function. In both types of plants, the efficiency of thermal dissipation of excess light declined in a time-dependent manner during combined stress treatment. This decline of NPQ can be due to inhibition of PSII activity and decrease in quantum efficiency of light conversion resulting in insufficient proton gradient to trigger energy dissipation in LHCII (Barényi and Krause 1985, Tjus and Andersson 1993, Popova et al. 2019).

In agreement with previous observations (Niyogi et al. 1997, 1998; Pogson et al. 1998, Lokstein et al. 2002), nontreated lut2 exhibited lower level of NPQ (37\%) in comparison to wt plants. It is generally considered that the main component of NPQ, $\mathrm{q}_{\mathrm{E}}$, is $\Delta \mathrm{pH}$ - and energydependent, rapidly reversible in darkness (Wraight and Crofts 1971, Horton et al. 1996, Ruban 2016), and is related to the de-excitation of ${ }^{1} \mathrm{Chl}^{*}$ and harmless dissipation of excess absorbed energy in LHCII (Müller et al. 2001). Not surprisingly, the lower level of NPQ strongly correlated with a similar decrease $(32 \%)$ of
$\mathrm{q}_{\mathrm{E}}$ in mutant plants (compare Figs. 5A,B; Fig. 6), which has been ascribed to disturbed assembly and structure of LHCII (Niyogi et al. 1997, Pogson et al. 1998, Lokstein et al. 2002).

The results presented in Fig. $4 D$ clearly showed that during the treatment with combined stress stimuli, a significant part of excess light was dissipated by constitutive thermal dissipation $\left(\Phi_{\mathrm{f}, \mathrm{D}}\right)$ that represents a part of the absorbed light energy that was not utilized by photochemistry or dissipated by NPQ. This type of energy dissipation represents an alternative and complementary pathway that utilizes the energy not dissipated by the major component $\left(\mathrm{q}_{\mathrm{E}}\right)$ of thermal dissipation mechanism NPQ that may be somehow restricted by exposure to low temperature (Savitch et al. 2009, Bag et al. 2020). It is very probable that the low temperature restricts functioning of NPQ as the xanthophyll cycle is dependent on the enzymatic conversion of violaxanthin to zeaxanthin by violaxanthin de-epoxidase.

Exposure of higher plants to cold stress diminishes the requirement for electrons for the process of $\mathrm{CO}_{2}$ fixation (Savitch et al. 2011 and references therein). In this study, we showed that the capacity to assimilate $\mathrm{CO}_{2}$ decreased after 6-d exposure to combined stress, stronger expressed in wt type plants (with $37 \%$ ) in comparison with lut 2 plants (the decrease was only 12\%) (Fig. 2A). At the same time, the increased excitation pressure on PSII (Fig. 4B) indicated that $\mathrm{Q}_{\mathrm{A}}$ and PQ pools were over-reduced in both types of plants as a result of development for $6 \mathrm{~d}$ under the combined stress. This suggestion is in accordance with results presented in Fig. $7 B$ indicating that the intersystem electron pool size from overexcitation of PQ pool and stromal reducing components $\left(\mathrm{e}^{-} / \mathrm{P}_{700}\right)$ (Asada et al. 1993), which can be donated to $\mathrm{P}_{700}{ }^{+}$, increased in a time-dependent manner. The stress-induced higher availability of intersystem electrons was diverted from the linear electron transport chain to PSI-dependent CEF for providing additional ATP for biochemical reactions and for protection of PSII against photodamage (Munekage et al. 2002). Indeed, after the exposure of wt and lut 2 plants to combined stress, an acceleration of the CEF was observed. A similar acceleration of CEF as a protective mechanism against photoinhibition at low temperature had been reported for Arabidopsis, wt (Ivanov et al. 2012, Popova et al. 2019).

The significant decrease of $\Phi_{\mathrm{NPQ}}$ is a clear indication that other photoprotective mechanisms might be involved in mitigating the effect of combined stress treatment in both wt and lut 2 plants. The observed significant increase of rates of re-reduction of $\mathrm{P}_{700}{ }^{+}$and constitutive (nonregulated) thermal dissipation $\left(\Phi_{\mathrm{f}, \mathrm{D}}\right)$, i.e., a fraction of absorbed light energy not utilized by photochemistry ( $\Phi_{\text {PSII }}$; Fig. 1S) or thermally quenched within the pigment bed of PSII $\left(\Phi_{\mathrm{NPQ}}\right)$, suggests that an enhanced capacity for $\mathrm{CEF}$ and $\Delta \mathrm{pH}$-independent photoprotective mechanisms were involved in photoprotection. Although no major differences in these parameters occurred between wt and lut 2 mutant after 2 and $6 \mathrm{~d}$ of stress treatments, it has to be mentioned that the initial capacity for CEF in lut2 (nontreated plants) was higher than that in nontreated wt 
plants (Fig. 7C; Popova et al. 2019), while the acceleration of CEF during stress treatments ( 2 and $6 \mathrm{~d}$ ) was higher in wt plants.

These results seem to contradict previous observations indicating a higher sensitivity of lut2 to high-light and low-temperature treatments (Dall'Osto et al. 2006). However, it should be noted that while higher light intensity $\left[1,400 \mu \mathrm{mol}\right.$ (photon) $\left.\mathrm{m}^{-2} \mathrm{~s}^{-1}\right]$, lower temperature $\left(4^{\circ} \mathrm{C}\right)$, and much longer treatments (3 weeks) were used in their study, we used milder short-term stress treatments [500 $\mu$ mol(photon) $\left.\mathrm{m}^{-2} \mathrm{~s}^{-1}, 12 / 10^{\circ} \mathrm{C}, 6 \mathrm{~d}\right]$, which may account for the different responses observed.

Conclusions: The experimental results demonstrating lower electrolyte leakage (Fig. 1), lower excitation pressure $\left(1-\mathrm{q}_{\mathrm{p}}\right.$; Fig. $\left.4 B\right)$, and higher $\Phi_{\text {PSII }}$ in lut 2 mutant (Fig. 1S) exposed to combined low-temperature and high-light treatment suggest that lut2 experiences overall a lower stress level compared to wt plants exposed to the same experimental conditions. In addition, the compromised three-dimensional structure of LHCII due to the lack of lutein (Lokstein et al. 2002) and the lower values of $\Phi_{\mathrm{NPQ}}$ (Fig. 4C) and $\mathrm{q}_{\mathrm{E}}$ (Fig. 6B) in lut2 plants under normal conditions and after treatment with two stress factors clearly indicated that photoprotective mechanism(s) localized within LHCII could not be involved in the acquisition of lower stress levels in lut 2 mutant. As an alternative, the observed enhanced capacity for CEF (Fig. 7C) and the higher oxidation state of $\mathrm{P}_{700}$ (Fig. 7A), which suggests PSI-dependent energy quenching (Bag et al. 2020), may serve as efficient photoprotective mechanisms, thus explaining the lower susceptibility of lut 2 to the stress treatments.

\section{References}

Allen D.J., Ort D.R.: Impacts of chilling temperatures on photosynthesis in warm-climate plants. - Trends Plant Sci. 6: 36-42, 2001.

Aro E.-M., Virgin I., Andersson B.: Photoinhibition of photosystem II. Inactivation, protein damage and turnover. BBA-Bioenergetics 1143: 113-134, 1993.

Asada K., Heber U., Schreiber U.: Electron flow to the intersystem chain from stromal components and cyclic electron flow in maize chloroplasts, as determined in intact leaves by monitoring redox change of P700 and chlorophyll fluorescence. - Plant Cell Physiol. 34: 39-50, 1993.

Bag P., Chukhutsina V., Zhang Z. et al.: Direct energy transfer from photosystem II to photosystem I confers winter sustainability in Scots pine. - Nat. Commun. 11: 6388, 2020.

Barényi G., Krause G.H.: Inhibition of photosynthetic reactions by light. A study with isolated spinach chloroplasts. - Planta 163: 218-226, 1985

Bravo L.A., Saavedra-Mella F.A., Vera F. et al:: Effect of cold acclimation on the photosynthetic performance of two ecotypes of Colobanthus quitensis (Kunth) Bartl. - J. Exp. Bot. 58: 3581-3590, 2007.

Croce R., Weiss S., Bassi R.: Carotenoid-binding sites of the major light-harvesting complex II of higher plants. - J. Biol. Chem. 274: 29613-29623, 1999.

Dall'Osto L., Fiore A., Cazzaniga S. et al.: Different roles of $\alpha$ - and $\beta$-branch xanthophylls in photosystem assembly and photoprotection. - J. Biol. Chem. 282: 35056-35068, 2007.
Dall'Osto L., Lico C., Alric J. et al.: Lutein is needed for efficient chlorophyll triplet quenching in the major LHCII antenna complex of higher plants and effective photoprotection in vivo under strong light. - BMC Plant Biol. 6: 32, 2006.

Demmig-Adams B., Adams W.W.: Photoprotection and other responses of plants to high light stress. - Annu. Rev. Plant Phys. 43: 599-626, 1992.

Dobrev K., Stanoeva D., Velitchkova M., Popova A.V.: The lack of lutein accelerates the extent of light-induced bleaching of photosynthetic pigments in thylakoid membranes of Arabidopsis thaliana. - Photochem. Photobiol. 92: 436-445, 2016.

Ensminger I., Busch F., Huner N.P.A.: Photostasis and cold acclimation: sensing low temperature through photosynthesis. - Physiol. Plantarum 126: 28-44, 2006.

Gerganova M., Popova A.V., Stanoeva D., Velitchkova M.: Tomato plants acclimate better to elevated temperature and high light than to treatment with each factor separately. Plant Physiol. Bioch. 104: 234-241, 2016.

Gilmore A.M.: Mechanistic aspects of xanthophylls cycledependent photoprotection in higher plant chloroplasts and leaves. - Physiol. Plantarum 99: 197-209, 1997.

Gray G.R., Savitch L.V., Ivanov A.G., Hener N.P.A.: Photosystem II excitation pressure and development of resistance to photoinhibition. II. Adjustment of photosynthetic capacity in winter wheat and winter rye. - Plant Physiol. 110: 61-71, 1996.

Guy C.L., Kaplan F., Kopka J. et al.: Metabolomics of temperature stress. - Physiol. Plantarum 132: 220-235, 2008.

Hendrickson L., Furbank R.T., Chow W.S.: A simple alternative approach to assessing the fate of absorbed light energy using chlorophyll fluorescence. - Photosynth. Res. 82: 73, 2004.

Horton P., Ruban A.V., Walters R.G.: Regulation of light harvesting in green plants. - Annu. Rev. Plant Phys. 47: 655684, 1996.

Huang H.Y., Zhang Q., Zhao L.P. et al.: Does lutein play a key role in the photoprotection of photosynthetic apparatus in Arabidopsis under severe oxidative stress? - Pak. J. Bot. 42: 2765-2774, 2010.

Huner N.P.A., Bode R., Dahal K. et al.: Shedding some light on cold acclimation, cold adaptation, and phenotypic plasticity. Can. J. Bot. 91: 127-136, 2013.

Huner N.P.A., Maxwell D.P., Gray G.R. et al.: Sensing environmental change: PSII excitation pressure and redox signaling. - Physiol. Plantarum 98: 358-364, 1996.

Huner N.P.A., Öquist G., Sarhan F.: Energy balance and acclimation to light and cold. - Trends Plant Sci. 3: 224-230, 1998.

Ivanov A.G., Morgan R.M., Gray G.R. et al.: Temperature/light dependent development of selective resistance of photoinhibition of photosystem I. - FEBS Lett. 430: 288-292, 1998.

Ivanov A.G., Rosso D., Savitch L.V. et al.: Implications of alternative electron sinks in increased resistance of PSII and PSI photochemistry to high light stress in cold-acclimated Arabidopsis thaliana. - Photosynth. Res. 113: 191-206, 2012.

Ivanov A.G., Sane P.V., Hurry V. et al.: Photosystem II reaction center quenching: mechanisms and physiological role. Photosynth. Res. 98: 565, 2008.

Ivanov A.G., Sane P.V., Krol M. et al.: Acclimation to temperature and irradiance modulates PSII charge recombination. - FEBS Lett. 580: 2797-2802, 2006.

Jahns P., Holzwarth A.R.: The role of xanthophylls cycle and of lutein in photoprotection of photosystem II. - BBABioenergetics 1817: 182-193, 2012.

Klughammer C., Schreiber U.: Analysis of light-induced absorbency changes in the near-infrared spectral region. 


\section{A.V. POPOVA et al.}

I. Characterization of various components in isolated chloroplasts. - Z. Naturforsch. 46: 233-244, 1991.

Kramer D.M., Johnson G., Kiirats O., Edwards G.E.: New fluorescence parameters for the determination of $Q_{A}$ redox state and excitation energy fluxes. - Photosynth. Res. 79: 209218, 2004.

Krieger A., Moya I., Weis E.: Energy-dependent quenching of chlorophyll $a$ fluorescence: effect of $\mathrm{pH}$ on stationary fluorescence and picosecond-relaxation kinetics in thylakoid membranes and Photosystem II preparations. - BBABioenergetics 1102: 167-176, 1992.

Lichtenthaler H.K.: Chlorophylls and carotenoids: pigments of photosynthetic biomembranes. - Method. Enzymol. 148: 350382, 1987.

Liu Z.F., Yan H.C., Wang K.B. et al.: Crystal structure of spinach major light-harvesting complex at $2.72 \AA$ resolution. - Nature 428: 287-292, 2004.

Lokstein H., Tian L., Polle J.E.W., DellaPenna D.: Xanthophyll biosynthetic mutants of Arabidopsis thaliana: altered nonphotochemical quenching of chlorophyll fluorescence is due to changes in Photosystem II antenna size and stability. BBA-Bioenergetics 1553: 309-319, 2002.

Long S.P., Humphries S., Falkowski P.G.: Photoinhibition of photosynthesis in nature. - Annu. Rev. Plant Phys. 45: 633642, 1994.

Miyake C., Horiguchi S., Makino A. et al.: Effects of light intensity on cyclic electron flow around PSI and its relationship to non-photochemical quenching of $\mathrm{Chl}$ fluorescence in tobacco leaves. - Plant Cell Physiol. 46: 1819-1830, 2005.

Müller P., Li X.P., Niyogi K.K.: Non-photochemical quenching. A response to excess light energy. - Plant Physiol. 125: 15581566, 2001.

Munekage Y., Hojo M., Meurer J. et al.: PGR5 is involved in cyclic electron flow around photosystem I and is essential for photoprotection in Arabidopsis. - Cell 110: 361-371, 2002.

Niyogi K.K., Björkman O., Grossman A.R.: The roles of specific xanthophylls in photoprotection. - P. Natl. Acad. Sci. USA 94: 14162-14167, 1997.

Niyogi K.K., Grossman A.R., Björkman O.: Arabidopsis mutants define a central role for the xanthophyll cycle in the regulation of photosynthetic energy conversion. - Plant Cell 10: 11211134,1998

Niyogi K.K., Shih C., Chow W.S. et al.: Photoprotection in a zeaxanthin- and lutein-deficient double mutant of Arabidopsis. - Photosynth. Res. 67: 139-145, 2001.

Peterman E.J.G., Dukker F.M., van Grondelle R., van Amerongen H.: Chlorophyll $a$ and carotenoid triplet states in light-harvesting complex II of higher plants. - Biophys. J. 69: 2670-2678, 1995.
Pogson B., McDonald K.A., Truong M. et al.: Arabidopsis carotenoid mutants demonstrate that lutein is not essential for photosynthesis in higher plants. - Plant Cell 8: 1627-1639, 1996.

Pogson B.J., Niyogi K.K., Björkman O., DellaPenna D.: Altered xanthophyll composition adversely affect chlorophyll accumulation and non-photochemical quenching in Arabidopsis mutants. - P. Natl. Acad. Sci. USA 95: 13324-13329, 1998.

Popova A.V., Dobrev K., Velitchkova M., Ivanov A.G.: Differential temperature effects on dissipation of excess light energy and energy partitioning in lut 2 mutant of Arabidopsis thaliana under photoinhibitory conditions. - Photosynth. Res. 139: 367-385, 2019.

Powles S.B.: Photoinhibition of photosynthesis induced by visible light. - Annu. Rev. Plant Phys. 35: 15-44, 1984.

Ruban A.V.: Nonphotochemical chlorophyll fluorescence quenching: Mechanism and effectiveness in protecting plants from photodamage. - Plant Physiol. 170: 1903-1916, 2016.

Savitch L.V., Ivanov A.G., Gudymaite-Savitch L. et al:: Effects of low temperature stress on excitation energy partitioning and photoprotection in Zea mays. - Funct. Plant Biol. 36: 37 49, 2009.

Savitch L.V., Ivanov A.G., Gudynaite-Savitch L. et al.: Cold stress effects on PSI photochemistry in Zea mays: Differential increase of FQR-dependent cyclic electron flow and functional implications. - Plant Cell Physiol. 52: 1042-1054, 2011.

Sonoike K., Kamo M., Hihara Y. et al.: The mechanism of the degradation of $p s a \mathrm{~B}$ gene product, one of the photosynthetic reaction center subunits of Photosystem I, upon photoinhibition. - Photosynth. Res. 53: 55-63, 1997.

Tjus S.E., Andersson B.: Loss of the trans-thylakoid proton gradient is an early event during photoinhibitory illumination of chloroplast preparations. - BBA-Bioenergetics 1183: 315 322,1993

van Kooten O., Snel J.F.H.: The use of chlorophyll fluorescence nomenclature in plant stress physiology. - Photosynth. Res. 25: $147-150,1990$.

von Caemmerer S., Farquhar G.D.: Some relationships between the biochemistry of photosynthesis and the gas exchange of leaves. - Planta 153: 376-387, 1981.

Walters R.G.: Towards an understanding of photosynthetic acclimation. - J. Exp. Bot. 56: 435-447, 2005.

Wei H., Yang Y.J., Zhang S.B.: Specific roles of cyclic electron flow around photosystem I in photosynthetic regulation in immature and mature leaves. - J. Plant Physiol. 209: 76-83, 2017.

Wraight C.A., Crofts A.R.: Delayed fluorescence and the highenergy state of chloroplasts. - Eur. J. Biochem. 19: 386-397, 1971.

(C) The authors. This is an open access article distributed under the terms of the Creative Commons BY-NC-ND Licence. 